\title{
Long-term efficacy of women participating in the curves fitness and weight loss program
}

\author{
Claire Canon", Julie Y Kresta, Mike Byrd, Jonathan M Oliver, Michelle Mardock, Sunday Simbo, Yanghoon Jung, \\ Majid Koozehchian, Deepesh Khanna, Brittanie Lockard, Ryan Dalton, Han K Kim, Chris Rasmussen, \\ Richard B Kreider
}

From International Society of Sports Nutrition; 7th Annual ISSN Conference and Expo Clearwater Beach, FL, USA. 24-26 June 2010

\section{Background}

The Curves fitness program involves a 30-minute circuit resistance-training program performed 3 days/week and an optional weight management program. While initial studies have shown this program to be highly effective (Nutri Metab 6/1/23, 2009), the long-term success rates of women participating in this program remains to be examined. This study examined the long-term efficacy of women participating in the Curves program from 6 months to 8 years on weight loss and maintenance.

\section{Methods}

Several long-time Curves franchise owners were invited to obtain consent from members of their clubs who had been a member for at least 6-months to participate in the study. Participants agreed to allow their weight and measurement member histories to be printed out and forwarded in an anonymous fashion to researchers. Member histories were examined to determine the amount, the time to peak weight and body fat loss (BIA), as well as length of time the weight loss was maintained. Participants were then stratified into length of involvement in the program as well as those who lost $<5 \%, 5-10 \%$, and $>$ than $10 \%$ body mass. Descriptive statistics were performed to determined percentage of members categorized by these groups. In addition, data were analyzed by ANOVA to examine differences among participants falling within these groups.

\section{Results}

Data were analyzed on 235 participants who were members for $36.9 \pm 22$ months, initially weighed $179 \pm 40 \mathrm{lbs}$, had

Exercise and Sport Nutrition Laboratory, Texas A\&M University, College Station, TX, USA a percent body fat of $38.6 \pm 6 \%$, and participated in an average of $329 \pm 230$ workouts. Mean peak weight loss was 13.5 \pm 12 lbs corresponding to a weight loss of $7.3 \pm 5 \%$ and a fat loss of $3.4 \pm 2.6 \%$. The average time to peak weight loss was $9.0 \pm 11$ months and weight loss was maintained an average of $10.4 \pm 13$ months. Participants who were members for 612 months (9\%) lost $8.7 \pm 6$ lbs and $2.6 \pm 1.5 \%$ fat; $1-2$ years (26\%) lost $13.3 \pm 13 \mathrm{lbs}$ and $3.3 \pm 2.8 \%$ fat; 2 -3 years $(23 \%)$ lost $11.1 \pm 9$ lbs and $3.0 \pm 2.0 \%$ fat; and, $>3$ years $(41 \%)$ lost $16.2 \pm 13 \mathrm{lbs}$ and $3.8 \pm 3.0 \%$ fat. When categorized by magnitude of weight loss, $42 \%$ of the participants lost less than $5 \%$ body mass $(3.2 \pm 1.2 \%), 35 \%$ lost $5-10 \%$ body mass $(7.0 \pm 1.3 \%)$, and $23 \%$ lost $>10 \%$ body mass $(15.3 \pm 5 \%)$. Participants in these groups lost $5.6 \pm 2.4,12.2 \pm 3.5$, and 29.8 $\pm 14.3 \mathrm{lbs}$ and $2.3 \pm 1.7,3.3 \pm 2.3$, and $5.3 \pm 3.4 \%$ fat, respectively. It took them $5.0 \pm 5,9.1 \pm 9$, and $15.9 \pm 16$ months to achieve the weight loss and it was maintained for $6.4 \pm 9$, $9.9 \pm 10$, and $15.9 \pm 16$ months. Overall, $29 \%$ of this cohort maintained weight loss for more than 1-year $(20.2 \pm 16 \mathrm{lbs}$, $10.2 \pm 7 \%$ weight, $25.2 \pm 16$ months [range $12-74$ months]).

\section{Conclusion}

These findings support contentions that women following the Curves program are experiencing significant benefits in terms of weight loss and maintenance.

\section{Acknowledgement}

This study was supported by Curves International, Waco, TX.

Published: 15 September 2010

doi:10.1186/1550-2783-7-S1-P11

Cite this article as: Canon et al:: Long-term efficacy of women

participating in the curves fitness and weight loss program. Journal of

the International Society of Sports Nutrition 2010 7(Suppl 1):P11. 